ADDIN, Vol. 10, No. 1, Februari 2016

\title{
GERAKAN RADIKALISME DALAM ISLAM: PERSPEKTIF HISTORIS
}

\author{
Anzar Abdullah \\ Universitas Pejuang Republik Indonesia (UPRI) Makassar, Sulawesi \\ Selatan, Indonesia \\ anzarabdullab91@yahoo.co.id
}

\section{Abstrak}

Jikalau kita membuka lembaran sejarah Islam di masa klasik, akan ditemukan fakta bahwa radikalisme sebagai suatu gerakan bukanlah fenomena baru dalam dunia Islam modern. Sebutlah sebuah aliran keagamaan dalam Islam, yaitu Khawarij adalah contoh aliran kalam yang paling terkenal dengan fahamnya yang radikal, dan tidak kenal kompromi. Hal ini dibuktikan dengan tindakan kekerasan dalam mencapai tujuannya, yaitu diantaranya melakukan pembunuban terhadap sababat Nabi pasca Perjanjian atau Tabkim (arbitrase) yang dianggap telah menyeleweng dari ajaran Tuhan.Untuk itulah, dalam usaha mengisi kurangnya kajian teologi Islam kontemporer dalam kaitannya dengan radikalisme, riset ini dibuat untuk melakukan analisis "bagaimana bubungan genealogis antara faham Khawarij di masa klasike dengan gerakan radikalisme Islam kontemporer sekarang ini". Analisis dilakukan melalui riset pustaka, dengan menelaah berbagai sumber tertulis yang terkait dengan radikalisme. Juga akan diuraikan beberapa terminology yang terkait dengan radikalisme dalam Islam. Supaya analisis kajiannya lebih focus, maka riset ini akan mengambil sampel Indonesia sebagai basis gerakan. Hal ini penting, untuk. melibat bubungan signifikansi radikalisme dalam sejarah Islam. Selain itu, di bagian akbir analisis penelitian, akan ditawarkan sebuah solusi dalam usaha mencegah perkembangan eskalasi gerakan 
Anzar Abdullah

radikalisme di Indonesia, dalam bentuk terapi radikalisme.

Kata Kunci: Gerakan, Radikalisme, Perspektif Sejarah.

\section{Abstract}

RADICALISM MOV EMENTIN ISL AM: A HISTORICAL PERSPECTIVE: If we open the history of Islam in the classical period, it will be found a fact that radicalism as a movement is not a new phenomenon in the modern Islamic world. Call it a religious sect in Islam as Khawarij is the most famous Kalam sect through radical understanding and uncompromising. This is evidenced by acts of violence to achieve its goals, as did the murder of the prophet's companions post-agreement or tabkim (arbitration). Which is considered to have deviated from the God's teachings. Therefore, in an effort to fill the lack of contemporary Islamic theology studies, in relation to radicalism, this research was conducted to analyze "how the relationship of genelogical between Khawarij understands in the classical period with contemporary radicalism movement of Islam today". The analysis is done through a literature review, by examining a variety of written sources related radicalism. Also outlined some of the terminology associated with Islam radicalism. To be more focused analysis, this research could take a sample of Indonesia as a base of movement. It is important to look at the significant relationship of radicalism in the history of Islam. And then, the last part of analysis indicated a solution in an effort to prevent the development of radicalism movement escalation in Indonesia, in the form of radicalism therapy.

Keyword: Radicalism, Movement, a Historical Perspective.

\section{A. Pendahuluan}

Walaupun istilah radikalisme diproduksi oleh Barat, namun gejala dan perilaku kekerasan itu dapat ditemukan dalam tradisi dan sejarah umat Islam. Fenomena radikalisme dalam Islam sebenarnya diyakini sebagai produk atau ciptaan abad ke-20 di dunia Islam, terutama di Timur Tengah, sebagai hasil dari krisis identitas yang berujung pada reaksi dan resistensi terhadap Barat yang melebarkan kolonialisme dan imperialime ke dunia Islam. Terpecahnya dunia Islam ke dalam berbagai Negara bangsa, dan proyek modernisasi yang dicanangkan oleh pemerintahan baru 
berhaluan Barat, mengakibatkanumatIslammerasakan terkikisnya ikatan agama dan moral yang selama ini mereka pegang teguh. ${ }^{1}$ Hal ini menyebabkan munculnya gerakan radikal dalam Islam yang menyerukan kembali ke ajaran Islam yang murni sebagai sebuah penyelesaian dalam menghadapi kekalutan hidup. Tidak hanya sampai disitu, gerakan ini melakukan perlawanan terhadap rezim yang dianggap secular dan menyimpang dari ajaran agama yang murni.

Selain Islam fundamentalisme, ada berbagai istilah yang digunakan oleh pengamat dan sarjana politik untuk mengidentifikasi dan menjelaskan fenomena radikalisme dalam Islam, baik dari masa klasik maupun hingga masa modern tentang kebangkitan Islam di dunia. Untuk itu, di dalam pembahasan akan diuraikan beberapa pengertian (terminology) radikalisme dalam Islam.

\section{B. Pembahasan}

\section{Radikalisme dalam Islam: Beberapa Terminologi}

Terminologiradikalisme dalam agama, apabila dihubungkan dengan istilah dalam bahasa Arab, sampai saat ini belum ditemukan dalam kamus bahasa Arab. Istilah ini adalah murni produk Barat yang sering dihubungkan dengan fundamentalisme dalam Islam. Dalam tradisi Barat istilah fundamentalisme dalam Islam sering ditukar dengan istilah lain, seperti: "ekstrimisme Islam" sebagaimana dilakukan oleh Gilles Kepel atau "Islam Radikal" menurut Emmanuel Sivan, dan ada juga istilah "integrisme, "revivalisme", atau "Islamisme". ${ }^{2}$ Istilah-istilah tersebut digunakan untuk menunjukkan gejala "kebangkitan Islam" yang diikuti dengan militansi dan fanatisme yang terkadang sangat ekstrim. Dibandingkan dengan istilah lainnya, "Islam radikal', yang paling sering disamakan dengan "Islam fundamentalis". Sebab istilah

${ }^{1}$ Penjelasan yang komprehensif mengenai basis sosial psikologis revivalisme Islam di Timur Tengah, dapat dilihat dalam R. Hrair Dikmejian, Islam in Revolution: Fundamentalism in Arab World (New York: Syracuse University Press, 1985), hlm. 25- 36.

${ }^{2}$ Lihat Junaidi Abdullah, "Radikalisme Agama: Dekonstruksi Ayat Kekerasan dalam al-Qur’an”, dalam Jurnal Kalam, Vol. 8, No. 2, Desember 2014, hlm. 3. 
fundamentalisme lebih banyak mengekspos liberalisme dalam menafsirkan teks-teks keagamaan, dan berakhir pada tindakan dengan wawasan sempit, yang sering melahirkan aksi destruktif, dan anarkis.

Esposito, seorang pakar tentang Islam, melakukan elaborasi mengenai istilah "fundamentalisme" dengan mengasosiasikan dengan tiga hal sebagai berikut: Pertama, dikatakan beraliran fundamentalis, apabila mereka menyerukan panggilan untuk kembali ke ajaran agama yang mendasar atau fonadasi agama yang murni; Kedua, pemahaman dan persepsi tentang fundamentalisme sangat dipengaruhi ole kelompok Protestan Amerika, yaitu sebuah gerakan Protestan abad ke-20 yang menekankan penafsiran Injil secara literal yang fundamental bagi kehidupan ajaran agama Kristen; Ketiga, istilah fundamentalisme dan anti Amerika. Esposito, kemudian berpendapat bahwa istilah fundamentalisme ini sangat bermuatan politis Kristen dan stereotype Barat, serta mengindikasikan ancaman monolitik yang tidak eksis. ${ }^{3}$ Oleh karena itu, Esposito tidak sependapat dengan kalangan Barat, mengenai istilah "fundamentalisme Islam", ia lebih cenderung untuk memakai istilah "revivalisme Islam" atau "aktivisme Islam" yang menurutnya tidak berat sebelah dan memiliki akar dalam tradisi Islam. ${ }^{4}$

Pendapat yang kurang lebih sama dengan Esposito, al-Asymawi menyatakan bahwa, penggunaan istilah fundamentalisme, tiada lain bertujuan untuk menjelaskan adanya tindakan ekstrimisme religious dalam Islam, bukan Islamnya yang fundamentalis. Oleh karena itu, tidak bisa disamakan atau diidentikkan atau disetarakan dengan ajaran agama Islam. Karena ajaran agama Islam tidak mereferensikan adanya tindakan kejahatan, radikalisme, ekstrimisme dengan cara-cara anarkis, seperti membom dan bunuh diri. ${ }^{5}$

3John L. Esposito, The Islamic Threat: Myth or Reality (New York: Oxford University Press, 1992), hlm. 8-9.

${ }^{4}$ Ibid.

${ }^{5}$ Lihat Muhammad Said al-Ashmawi, Agains Islamic Extremism: the Writings of Muhammad Said al-Ashmawi (Florida: University Press of Florida, 1998), hlm. 21. 
Sementara itu, Yusuf al-Qaradhawi, memberikan istilah radikalisme dengan istilah al-Tatarruf ad-Din. Atau bahasa lugasnya adalah untuk mempraktikkan ajaran agama dengan tidak semestinya, atau mempraktikkan ajaran agama dengan mengambil posisi tarf atau pinggir. Jadi jauh dari substansi ajaran agama Islam, yaitu ajaran moderat di tengah-tengah. Biasanya posisi pinggir ini adalah sisi yang berat atau memberatkan dan berlebihan, yang tidak sewajarnya. Lanjut al-Qaradhawi, posisi praktik agama seperti ini setidaknya mengandung tiga kelemahan, yaitu: pertama, tidak disukai oleh tabiat kewajaran mansia; kedua, tidak bisa berumur panjang, dan yang ketiga, ialah sangat rentan mendatangkan pelanggaran atas hak orang lain. ${ }^{6}$ Apa makna dari implikasi cara beragama seperti ini, ialah bahwa dalam praktik pengalaman beragama terdapat orang-orang berperilaku ekstrim, sehingga melebihi kewajaran yang semestinya.

\section{Akar Sejarah Radikalisme dalam Islam}

Sejarah perilaku kekerasan dalam Islam, umumnya terjadi berkaitan dengan persoalan politik, yang kemudian berdampak kepada agama sebagai smbol. Hal ini adalah fakta sejarah yang tidak terbantahkan. Walaupun pembunuhan terhadap khalifah telah terjadi ketika Khalifah Umar berkuasa. Namun, gerakan radikalisme yang sistematis dan terorganisir baru dimulai setelah terjadinya Perang Shiffin di masa kekuasaan Ali bin Abi Thalib. Hal ini ditandai dengan munculnya sebuah gerakan teologis radikal yang disebut dengan "Khawarij". Secara etimologis, kata khawarij berasal dari bahasa Arab, yaitu "kharaja" yang berarti keluar, muncul, timbul, atau memberontak. Dari pengertian ini, kata tersebut dapat juga dimaknai sebagai golongan orang Islam atau Muslim yang keuar dari kesatuan umat Islam. Ada pula yang mengatakan bahwa pemberian nama itu di dasarkan pada Q.S. an-Nisa' [4]: 100 Surat Annisa ayat 100, yang menyakatan: "Keluar dari rumah kepada Allah dan Rasulnya". Dengan kata

Lihat juga Nazih Ayyubi, Political Islam: Religion and Politics in the Arab World (London and New York: Routledge, 1991), hlm. 67.

${ }^{6}$ Lihat Yusuf al-Qardhawi, al-Sahwah al-Islamiyyah: $\bar{B}$ aina al-Juhad wa al-Tatarruf (Kairo: Bank at-Taqwa, 2001), hlm. 23-29. 
lain, golongan "Khawarij" memandang diri mereka sebagai orang yang meninggalkan rumah atau kampung halaman untuk "berhijrah" dan mengabdikan diri kepada Allah dan Rasul-Nya."

Dalam konteks teologi Islam, Khawarij berpedoman kepada kelompok atau aliran kalam yang berasal dari pengikut Ali bin Abi Thalib yang kemudian keluar dari barisannya, karena ketidaksetujuannya terhadap keputusan Ali yang menerima arbitrase (tahkim) ataupun perjanjian damai dengan kelompok pemberontak Mu'awiyah bin Abi Sufyan mengenai persengketaan kekuasaan (khilafah). Menurut kelompok Khawarij, keputusan yang diambil Aliadalah sikap yang salah dan hanya menguntungkan kelompok pemberontak. Situasi inilah yang melatarbelakangi sebagian barisan tentara Ali keluar meninggalkan barisannya. ${ }^{8}$

Arbitrase terjadi dalam konteks Perang Shiffin, antara kelompok Ali bin Abi Thalib dengan kelompok Mu'awiyah bin Abi Sufyan sebagai hasil dari pertikaian politik pasca kematian Khalifah Usman bin Affan. Sebagaimana di dalam sejarah, ketika Ali terpilih menjadi khalifah, ia mendapatkan tantangan dari beberapa pemuka sahabat yang ingin menjadi khalifah, di antaranya ialah Mu'awiyah bin Abi Sufyan, Gubernur Damaskus waktu itu. Mu'awiyah tidak mengakui Ali sebagai khalifah, sebagaimana juga Talhah dan Zubair. Mereka menuntut kepada Ali, agar menghukum pembunuh Khalifah Usman bin Affan, bahkan mereka menuduh Ali bin Abi Thalib turut terlibat dalam pembunuhan itu. Salah seorang pemuka pemberontak dari Mesir yang datang ke Madinah, dan kemudian membunuh Usman bin Affan, adalah Muhammad Ibn Abi Bakr, anak angkat dari Ali bin Abi Thalib. Selain itu, Ali tidak mengambil tindakan keras terhadap pemberontak, bahkan Muhammad Ibn Abi Bakr ditunjuk dan diangkat menjadi Gubernur Mesir. ${ }^{9}$

${ }^{7}$ Achmad Gholib, Teologi dalam Perspektif Islam (Jakarta: UIN Jakarta Press, 2005), hlm. 47.

${ }^{8}$ Lihat Azyumardi Azra, Pergolakan Politik Islam (Bandung: Mizan, 1999), hlm. $112-113$.

${ }^{9}$ Harun Nasution, Teologi Islam: Aliran-aliran Sejarah, Analisa Perbandingan (Jakarta: UI Press, 1986), hlm. 4-5. 
Pertikaian politik tersebut mencapai puncaknya dalam perang besar antara pasukan Ali bin Abi Thalib dengan pasukan Mu'awiyah bin Abi Sufyan di Shiffin. ${ }^{10}$ Pasaukan Ali dapat mendesak dan memukul mundur tentara Mu'awiyah, sehingga pasukan Mu'awiyah, Amir ibn al-Ash yang terkenal sebagai orang yang licik, meminta berdamai dengan mengangkat al-Qur'an ke atas. Seorang sahabat dari kelompok Ali yang bernama Qurra' mendesak Ali supaya menerima tawaran itu. Dengan permintaan itu, dicarilah kerangka perdamaian dengan mengadakan arbitrase (tahkim) di antara kedua belah pihak. Sebagai perantara, diangkat dua orang: Amir bin al-Ash dari pihak Mu'awiyah dan Abu Musa al-Asy'ari dari pihak Ali. Sejarah mencatat, bahwa dalam perjanjian damai itu, kedua belah pihak menandatangani kesepakatan untuk tidak menjatuhkan kedua pemuka sahabat yang bertentangan itu. Tetapi, karena kelicikan Amir bin al-Ash, arbitrase tersebut menguntungkan pihak Mu'awiyah, karena ia mengumumkan hanya menyetujui pemakzulan Ali bin Abi Thalib yang diumumkan lebih dulu oleh Abu Musa al-Asy'ari, dan menolak menjatuhkan Mu'awiyah. Akibatnya, kedudukan Mu'awiyah naik menjadi Khalifah yang tidak resmi alias tidak sah. ${ }^{11}$

Jadi Khawarij, sebagai sebuah kelompok sempalan dalam Islam yang berpikir radikal, merupakan sebuah bentuk yang lahir dari kekecewaan politik terhadap arbitrase yang merugikan kelompok Ali bin Abi Thalib. Akhirnya, sebagain dari pendukung Ali keluar, dan berpendapat ekstrim bahwa perang tersebut tidak dapat diselesaikan dengan tahkim manusia. Tetapi putusan hanya datang dari Allah swt dengan cara kembali kepada hukum yang ada di dalam al-Qur'an dan Sunnah Nabi. Semboyan mereka adalah La bukma Illa Lillah (tidak ada hukum selain hukum Allah). Mereka, yang keluar dari kelompk Ali bin Abi Thalib ini, yang kemudian menamakan dirinya golongan "Khawarij" memnadnag dan mencap bahwa Ali bin Abi Thalib, Amir bin al-Ash, Abu Musa al-Asy'ari, dan Mu'awiyah, serta yang lainnya

${ }^{10}$ Philip K. Hitti, History of the Arabs (London and Basingstoke: The MacMillan Press Ltd, 1974), hlm. 181-183.

${ }^{11}$ Ibid. Lihat juga Syamsul Rijal, "Radikalisme Klasik dan Kontemporer", dalam Alfiker, Vol. 228 (14), No. 2, 2010, hlm. 7. 
yang setuju atau menerima arbitrase atau tahkim adalah sebagai kafir, karena tidak kembali ke al-Qur'an dalam menyelesaikan pertikaian tersebut.

Persoalan kafir ini menjadi dasar awal persoalan teologis dalam Islam, di mana kelompok "khawarij" adalah pendirinya. karena mereka memandang sahabat yang terlibat dalam arbitrase itu adalah kafir, maka berarti mereka diklaim kluar dari Islam alias murtad, dan karena itu halal darahnya untuk dibunuh. Akhirnya, sebagaimana terbukti dalam sejarah, akhirnya Khalifah Ali bin Abi Thalib berhasil dibunuh.

Radikalisme Khawarij sebagai pemberontak telah terbukti dalam sejarah. Tidak hanya di masa Ali, Khawarij meneruskan perlawananya terhadap kekuasaan Islam resmi, baik di zaman Dinasti Bani Umayyah maupun Abbasiyah. Oleh karena itu, mereka memilih Imam sendiri dan membentuk pemerintahan kaum Khawarij. ${ }^{12}$ Radikalisme gerakan ini bukan saja pada aspek pemahaman, tetapi juga pada aspek tindakan. Khawarij memahami ajaran Islam secara harfiyah, sebagaimana terdapat dalam al-Qur'an dan Hadis Nabi; dan mereka merasa wajib melaksanakannya tanpa perlu penafsiran macam-macam. Alamat kafir dan musyrik dialamatkan oleh kaum Khawarij kepada siapa saja orang yang tidak sepaham dengan golongannya, bahkan terdapat orang yang sepaham tetapi tidak mau hijrah ke daerah mereka. Bahkan mereka menyebutnya sebagai "dar al-harb", sehingga dapat dibunuh. ${ }^{13}$ Berhubung dengan perbuatan yang sangat kejam itu, Azyumardi Azra menyebut aksi kaum Khawarij sebagai isti'rad, yaitu eksekusi keagamaan, bukan sebuah jihad. ${ }^{14}$

Dari rekaman sejarah tersebut, dapat dilihat bahwa fundamentalisme lebih menekankan pada pembenaran dalam menggunakan kekerasan atas nama agama. Islam dianggap mengajarkan para pemeluknya yang fanatic untuk melakukan

${ }^{12}$ Harun Nasution, Islam Rasional: Gagasan dan Pemikiran Prof. Dr. $\bar{H}$ arun Nasution (Bandung: Mizan, 1996), hlm. 124.

${ }^{13}$ Gholib, Teologi dalam Perspektif Islam, hlm. 52.

${ }^{14}$ Azyumardi Azra, Pergolakan Politik Islam: dari Fundamentalisme, Modernisme, hingga Post-Modernisme (Jakarta: Paramadina, 2006), hlm. 141. 
tindakan kekerasan sebagai manifestasi dari keimanan. Dari peristiwa semacam itulah, kemudian ada sebagian orang yang membayangkan adanya sekelompok umat Islam yang meyakini bahwa Tuhan telah menyuruhnya untuk melakukan segala tindakan untuk membela agamanya, meskipun salah jalan, bertentangan dengan nilai-nilai ajaran Islam universal yang toleran, dan akomodatif.

\section{Radikalisme dalam Islam Era Kontemporer}

Bagaimana gerakan radikalisme atau fundamentalisme dalam Islam dewasa ini, era kontemporer? Tampaknya lebih banyak dipengaruhi respon Islam atas Barat. Walaupun tematema yang berkaitan dengan inward oriented tetapi menjadi concern dan pilihan ideologis mereka. Paling tidak ada dua masalah besar yang menjadi perhatian kelompok ini. Pertama, mereka menolak sekularisme masyarakat Barat yang memisahkan agama dan politik, gereja, dan masjid dari Negara. Kesuksesan Barat melakukan sekularisasi dianggap sebagai sesuatu yang berbahaya, karena dapat mengancam Islam sebagai agama yang tidak hanya mengurusi persoalan akhirat saja, tetapi sekaligus duniawi. Kedua, banyak umat Islam yang menginginkan agar masyarakat mereka diperintah sesuai dengan al-Qur'an dan syari'at Islam sebagai aturan bernegara. ${ }^{15}$ Oleh krena itu, dewasa ini tidak mengherankan, apabila muncul gerakan bawah tanah yang bercita-cita membangun khilafah Islamiyah dengan mengusung tema-tema kedaulatan Tuhan, jihad, revolusi Islam, keadilan sosial, dan sebagainya. Tema-tema tersebut diorientasikan pada masa lampau, khususnya generasi awal Islam sebagaimana yang dipraktikkan ole Nabi Muhammad saw dan para sahabat. Karena mereka menganggap bahwa masayarakat Islam dewasa ini menglami kemunduran, karena tidak lagi melakasanakan ajaran agamanya secara murni. Karenanya agenda di atas harus dilakukan untuk melawan hegemoni Barat sambil membayangkan

${ }^{15}$ Lihat Karen Amstrong, Berperang Demi Tuban: Fundamentalisme dalam Islam, Kristen dan Yabudi (Jakarta: Serambi, 2001), hlm. ix. Lihat juga Leonard Binder, Islamic Liberalism: a Critique of Development Ideologies (Chicago and London: The University of Chicago Pres, 1988), hlm. 16-49. 
romantisme masa lalu, agar kejayaan Islam dapat tercipta di zaman modern ini.

Bertolak dari pemaparan sejarah tersebut, dapat dikatakan bahwa fundamentalisme dalam Islam dan juga agama lain, memiliki karakteristik yang membedakannya dengan kelompok lain. Pertama, skripturalisme, yaitu keyakinan harfiah terhadap kitab suci yang merupakan firman Tuhan, dan dianggap tidak mengandung kesalahan. Kedua, penolakan terhadap hermeneutika. Teks-teks Al-Qur'an dalam pandangan kelompok ini, harus dipahami secara literal sebagaimana bunyinya atau redaksinya. Nalar dipandang tidak mampu memberikan interpretasi yang tepat terhadap teks, bahkan terhadap teks yang satu sama lain bertentangan sekalipun. Ketiga, penolakan terhadap pluralisme dan relativisme yang dianggap merongrong kesucian teks. Keempat, penolakan terhadap perkembangan historis sosiologis yang dianggap membawa manusia semakin jauh dari doktrin literal kitab suci. Kelima, monopoli kebenaran atas tafsir agama. Kaum fundamentalisme radikal, biasanya cenderung menganggap dirinya sebagai penafsir yang paling sah dan absah, sehingga cenderung memandang sesat kepada kelompok lain yang tidak sealiran. ${ }^{16}$

Contoh kasus Indonesia, gerakan Islam radikal kontemporer, dapat disebutkan di sini, antara lain Hizbut Tahrir Indonesia (HTI). Organisasi ini bersifat radikal dalam hal ide politiknya, namun menekankan cara-cara damai untuk mencapai tujuannya. Radikalismenya tergambar dari perjuangan HTI yang menginginkan perubahan politik fundamental melalui penghancuran total Negara-bangsa sekarang ini, dan menggantinya dengan Negara Islam baru di bawah satu komando khilafah. ${ }^{17}$

${ }^{16}$ Martin E. Marty, "What is Fundamentalisme? Theological Perspective", dalam Hans Kun dan Jurgen Moltmann (eds.), Fundamentalism as a Cumanical Challenge (London: Mac Millan, 1992), hlm. 3-13.

${ }^{17}$ Karagiannis dan Clark Mc Cauley, "Hizbut Tahrir al-Islami: Evaluating the Threat Posed by a Radical Islamic Group that Remannis Non Violence", dalam Terrorism and Political Violence, No. 58 (2006), hlm. 318. 
HTI dalam melancarkan gerakannya, tidak secara frontal seperti organisasi Islam radikal lainnya, seperti Majelis Mujahidin Indonesia (MMI) atau Anshorud Taubid pimpinan Abu Bakar Ba'asyir. Tetapi HTI melancarkan gerakannya dengan bertahap. Untuk kasus Indonesia ini, belum ada bukti yang kuat menunjukkan keterlibatan HTI dalam tindak kekerasan dan terorisme. Oleh karena itu, penting untuk memahami aktivitas dan keterkaitannya dengan aksi jihad. Ada tiga tahap atau tiga langkah HTI dalam upaya mencapai tujuan politiknya, yaitu:

(a) Tahap Tatsqif (pembinaan dan pengkaderan). Tahap ini untuk melahirkan orang-orang yang meyakini fikrah Hizbut Tahrir dan untuk membentuk kerangka sebuah partai. (b) Tahap Tafa'ul (interaksi), yaitu berinteraksi dengan umat agar mampu mengemban dakwah Islam, sehingga umat akan menjadikannya sebagai masalah utama dalam kehidupannya, serta berusaha menerapkannya dalam realitas kehidupan. (c) Tahap Istilamul Hukmi (pengambil alihan kekuasaan). Tahap ini berfungsi untuk menerapkan hukum Islam secara praktis dan totalitas, sekaligus untuk menyebar luaskan ke seluruh dunia. ${ }^{18}$

Ketiga tahap inilah yang dipakai oleh HTI dalam usahanya mencapai tujuan pendirian Negara Islam. Hal ini mengindikasikan bahwa perjuangan HTI dimulai dari bawah. Karena itu organisasi ini sangat aktif dalam perekrutan anggota, proses pengkaderan, dan penyebaran informasi melalui media massa, famplet, seminar dan demonstrasi jalanan sebagai bagian dari langkah-langkah strategis untuk mencapai tujuan pembentukan khilafah.

Membandingkan kelompok radikalisme Islam era klasik, yang dimotori golongan Khawarij dengan konteks gerakan Islam radikal kontemporer, seperti Hizbut Tahrir dari sudut ilmu kalam, memang sangat kompleks. Hal ini dikarenakan kelompok yang pertama bersifat lebih teologis, sementara yang kedua sifatnya sangat politis. Tetapi, jika dilihat dari perspektif kajian radikalisme, khususnya secara doctrinal dan sosiologis, kita

${ }^{18}$ Hizbut Tahrir Organization, The Methodology of Hizbut Tabrir for Change (London: al-Khilafah Publikation, 1999), hlm. 32. 
dapat menemukan beberapa kesamaan atau pun kemiripan, yang oleh Marty dan Appleby disebutnya sebagai "family resemblences" di antara keduanya.

Dari segi perbedaan konteks dan tahap radikalisme, bahwa kedua gerakan ini memiliki akar sejarah kemunculan yang berbeda. Khawarij muncul sebagai reaksi kekecewaan terhadap peristiwa tahkim yang akhirnya menguntungkan pihak musuh (Muawiyah). Justifikasi teologisnya, bahwa Ali bin Abi Tahlib dan pendukungnya sesungguhnya telah menentang kedaulatan Tuhan, karena tidak menggunakan hukum Allah, sebuah klaim yang sebenarnya juga masih abstrak. Pemahaman yang eksklusif ini kemudian membawa mereka kepada pengkafiran dan tindak kekerasan terhadap orang di luar kelompoknya. Ciri utama radikalisme Khawarij bersifat ke dalam, ketimbang keluar. Target kekerasan Khawarij bukanlah pihak luar (non Muslim), namun kelompok Islam sendiri yang dianggap telah menyimpang dari Islam, atau memiliki pemahaman keagamaan Islam yang berbeda dengan kelompoknya. Dalam rekaman sejarah, Khawarij banya berperan sebagai pemberontak yang aktif melancarkan serangan terror dan kekerasan terhadap dinasti Islam yang berkuasa, baik di masa daulah Abbasiyah maupun Umayyah.

Berbeda dengan organisasi Hizbut Tahrir yang lahir di masa kontemporer sekarang ini. Organisasi ini adalah fenomena modern yang muncul sebagai reaksi terhadap ancaman dari luar ketimbang dari dalam Islam sendiri. Organisasi Hizbut Tahrir sebagai gerakan politik dalam Islam, kelahirannya lebih banyak dimotivasi oleh faktor perlawanan terhadap dominasi dan hegemoni Barat melalui proyek kolonisasi yang menjajah negeri-negri Muslim di dunia. Menurut, Azyumardi Azra, fundamentalisme dan radikalisme kontemporer bangkit sebagai reaksi terhadap penetrasi sistem dan nilai sosial, budaya, politik, dan ekonomi Barat, baik sebagai akibat kontak langsung dengan Barat maupun melalui pemikir Muslim. Tegasnya, kelompok modernis, sekularis, dan westernis atau rezim pemerintahan Muslim yang menurut kaum fundamentalis merupakan perpanjangan mulut 
dan tangan Barat. ${ }^{19}$ Karena itulah wacana yang diangkat oleh Hizbut Tahrir, khususnya HTI di Indonesia cenderung anti Barat yang diterjemahkan dalam slogan atau semboyan perlawanan anti imperialisme, anti kolonialisme, dan anti kapitalisme. Sebagai anti tesis Barat, HTI selalu mengagungkan keunggulan Islam dengan berbagai aspeknya yang komprehensif. Hizbut Tahrir lebih menekankan terjadinya benturan budaya, ketimbang dengan cara dialog budaya dan harmoni antara Islam dan Barat.

\section{Pentingnya Dekonstruksi Tafsir atas Radikalisme}

Satu hal yang penting dilakukan oleh para tokoh agama, mulai dari ulama, guru agama di sekolah, kiai di pondok pesantren, dan dosen agama di perguruan tinggi, sangat penting untuk menjelaskan tentang pengertian konsep jihad dalam Isam yang sebenarnya. Hal ini, tentu sangat berkaitan dengan maraknya tindakan radikalisme atas nama agama, yang sering kali diidentikkan dengan jihad di jalan Allah.

Sebagai doktrin agama, jihad merupakan media doktrinalisasi yang berfungsi sebagai alat perjuangan agama dalam menjawab tantangan zaman. Hal yang perlu disadari, bahwa jihad bukanlah produk otoritas individu atau penafsiran organisasi tertentu, melainkan produk dari berbagai individu, dan menafsirkannya serta menerapkan dalam prinsip-prinsip hidup dalam konteks khusus secara historis politis. Untuk itu kita harus membaca dan memahami ayat-ayat al-Qur'an secara historis. Misalnya, kita dapat melihat ayat-ayat al-Qur'an yang membahas tentang jihad dalam Q.S. al-Ankabut [29]: 69 yang artinya: "Dan mereka yang berjuang di jalan Kami, dan sesungguhnya Tuhan bersama mereka yang berbuat kebaikan", begitu juga di dalam

\footnotetext{
${ }^{19}$ Azyumardi Azra, Pergolakan Politik Islam: dari Fundamentalisme, Modernisme, bingga Post Modernisme (Jakarta: Paramadina, 2006), hlm. 111. Lihat juga Greg Fealy, "Hizbut Tahrir Indonesia: Seeking Total Islamic Identity", dalam Shahram Akbarzadeh dan Fethi Mansouri (eds.), Islam and Political Violence: Muslim Diaspora and Radicalism in the West (London and New York: Tauris Academic Studies, 2007), hlm. 154. Periksa juga Taji Farouki, "Islamist and Threat of Jahid: Hizb al-Tahrir and alMuhajiroun on Israel and Jews", dalam Middle Eastern Studies, 36:4 (Oktober 2000), hlm. 2; A Fundamentalism Quest: Hizb al-Tahrir and the Search for the Islamic Caliphate (London: Grey Seal, 1996), hlm. 1-2.
} 
Q.S. al-Hajj [22]: 78 yang artinya "Dan berjuanglah untuk Allah dengan sungguh-sungguh”, serta dalam Q.S. al-Baqarah [2]: 190, yang artinya "Dan perangilah di jalan Allah orang-orang yang memerangi kamu, tetapi janganlah kamu melampaui batas, karena sesungguhnya Allah tidak menyukai orang-orang yang melampaui batas", ${ }^{20}$

Kandungan ayat-ayat al-Qur'an di atas, menekankan konsep jihad sebagai perjuangan yang inhern dengan kesulitan dan kerumitan menuju kehidupan yang lebih baik. Berjuang melawan hawa nafsu di dalam diri sendiri dalam rangka mencapai keutamaan hidup, kemakmuran, kesejahteraan baik secara ekonomi, politik dan sosial budaya. Oleh karena itu, menarik untuk disimak pernyataan Asghar Ali Engginer, tentang konsep jihad dalam Islam dengan mengatakan:

"In fact as far the Qur'an is concerned of "jihad" has nothing to do with violence. The Qur'an does not use this word in any sense of war at all. It is much later usage with which we are not concerned here. It is highly regrettable that not only non muslim even Muslims in general think that the Qur'an uses the term jihad for war and that is duty of Muslims to wage jihad (i.e. in the sense of war) in the way of Allah. The word jihad unfortunately has been so misused in the history of Muslims that even an Arabic dictionary al-Qamus al-Asri by Ellian Anton (Cairo, 1972) gives its meanings are distorted throught popular practice". ${ }^{21}$

Pernyataan Asghar di atas, sekali lagi menegaskan bahwa konsep jihad dalam Islam sangat tidak identik dengan kekerasan dan radikalisme. Distorsi makna jihad, tampaknya telah dilakukan oleh Ellian Anton dengan kamusnya, yang memaknai jihad sama

${ }^{20}$ Lihat Abu Rokhmadi, "Radikalisme Islam dan Upaya Deradikalisasi Paham Radikal”, dalam Jurnal Walisongo, Vol. 20, No. 1, Mei 2012, hlm. 20-21. Lihat juga Junaidi Abdullah, "Radikalisme Agama", dalam Jurnal Kalam, Vol. 8, No. 2, Desember 2014, hlm. 8-9.

${ }^{21}$ Lihat Asghar Ali Engineer, "Islam and Doctrines of Peace and NonViolence", dalam Jurnal Internasional Ihya Ulumuddin, Program Pascasarjana IAIN Walisongo, Vol. 3, Semarang: Walisongo Press, 2001, hlm. 121. Lihat juga Jajang Jahroni dan Jamhari, Gerakan Salafi Radikal di Indonesia (Jakarta: Rajawali Press, 2004), hlm. 2-3. 
dengan perang suci atas nama agama. Padahal, bila dilacak lebih dalam kata "jihad" yang berasal dari kata jahada dan berbagai derivasinya, tidak ada satupun yang menjelaskan bahwa jihad erat hubungannya dengan radikalisme dan terorisme.

Memang istilah "jihad" atau kata "jihad" dapat dijumpai dalam ayat-ayat al-Qur'an, antara lain dalam Q.S. at-Taubah [9]: 24, yang artinya: "Katakanlah, jika bapak-bapakmu, anakanakmu, saudara-saudaramu, isteri-isterimu, keluargamu, harta kekayaan yang kamu usahakan, perdagangan yang kamu khawatirkan kerugiannya, dan rumah-rumah tempat tinggal yang kamu sukai, lebih kamu cintai daripada Allah dan RasulNya, serta berjihad di jalan-Nya, maka tunggulah sampai Allah memberi keputusan. Dan Allah tidak memberi petunjuk orangorang yang fasik." Kata jihad juga terdapat dalam Q.S. al-Hajj [22]: 78, yang artinya: "Dan berjihadlah kamu di jalan Allah dengan jihad sebenar-benarnya. Dia telah memilih kamu dan Dia menjadikan kesukaran untukmu dalam agama, ikutlah agama nenek moyangmu Ibrahim". Selanjutnya kata jihad juga ditemukan dalam Q.S. al-Mumtahanah [60]: 1, yang artinya: "Jika kamu benar-benar keluar untuk berjihad pada jalan-Ku dan mencari keridhaan-Ku (janganlah kamu berbuat demikian), kamu memberikan secara rahasia (berita-berita Muhammad) kepada mereka, karena rasa kasih sayang dan Aku lebih mengetahui apa yang kamu sembunyikan dan apa yang kamu nyatakan."

Kata jihad juga ditemukan dalam Q.S. at-Taubah [9]: 19, yang artinya: "apakah (orang-orang) yang memberi minuman kepada orang-orang yang mengerjakan haji dan mengurus Masjid al- haram kamu samakan dengan orang yang beriman kepada Allah, dan hari kemudian, serta berjihad di jalan Allah? Mereka itu tidak sama di sisi Allah. Allah tidak memberikan petunjuk kepada orang-orang yang zalim".

Dalam Q.S. al-Hujurat [49]: 1, juga ditemukan kata jihad, yang artinya: "Sesungguhnya orang-orang yang sebenarnya adalah mereka yang beriman kepada Allah dan Rasul-Nya, kemudian mereka tidak ragu-ragu dan mereka berjihad dengan harta dan jiwanya di jalan Allah. Mereka itulah orang-orang yang 
benar.” Kata jihad juga muncul dalam Q.S. al-Ankabut [29]: 6, yang artinya: "Dan barang siapa berjihad, maka sesungguhnya jihadnya untuk dirinya sendiri. Sungguh Allah maha kaya dari seluruh alam."

Selain itu, perlu juga dikemukakan di sini, bahwa selain kata jihad, di dalam al-Qur'an juga terdapat kata-kata perang, peperangan dan bermacam derivasinya, seperti istilah qatala dan qital. Misalnya dapat dijumpai dalam Q.S. al-Hajj [22]: 30-40, yang artinya: "Telah diizinkan berperang kepada mereka yang diperangi, oleh karena mereka sesungguhnya dianiaya, dan sesungguhnya Allah Maha berkuasa menolong mereka. Yaitu, orang-orang yang diusir keluar dari kampungnya dengan tidak ada sesuatu alasan yang patut, kecuali mereka berkata: "Tuhan kami adalah Allah". Ini adalah ayat pertama kali turun yang terkait dengan doktrin peperangan dan kekerasan dalam Islam.

Tetapi ayat tersebut ditafsirkan oleh pakar sejarah Ahmad Syalabi, seorang Profesor sejarah dari Universitas Kairo Mesir, dengan mengatakan bahwa siapa yang mau mendalami ayat tersebut maka dia akan melihat bahwa Islam sebenarnya tidak menginginkan peperangan. Menurutnya, kata peperangan dalam ayat ini, hanyalah sebatas pemberian izin bagi mereka yang dizalimi dengan kata-kata "bi annahum-dzulimu” (karena sesungguhnya mereka dianiaya). Karenanya, sewaktu ayat ini turun, beberapa di antara kaum Muslimin sahabat Nabi belum cukup yakin dengan ayat ini untuk dijadikan alasan untuk melakukan peperangan. ${ }^{22}$

Walaupun pada ayat ini pemberian izin itu tidaklah mutlak, melainkan bersyarat bahwa peperangan itu haruslah untuk membela diri, dan sama sekali tidak dibolehkan melampaui batas kemanusiaan yang dapat menimbulkan kemarahan Allah swt. Dalam konteks peperangan, bila ditinjau dari sejarahnya, Islam memberikan dasar-dasar dalam peperangan membela diri, kehormatan, menjamin kelancaran dakwah dan menjamin kesempatan yang mau menganut Islam serta untuk menjaga

${ }^{22}$ Lihat Ahmad Syalabi, Sejarah dan Kebudayaan Islam, jilid 1 (Jakarta: Pustaka al-Husna, 1994), hlm. 154. 
sekaligus memelihara umat Islam dari serangan kekuatan Persia dan Romawi saat itu. ${ }^{23}$

Pemaparan dan analisis tematik dari ayat-ayat al-Qur'an di atas yang mempunyai kaitan dengan konsep jihad, tidak ada satupun yang berkonotasi untuk berperang dan melegalkan tindak kekerasan dalam menyelesaikan setiap persoalan. Sebaliknya konsep jihad, justru semata-mata diperuntukkan meningkatkan nilai ibadah kepada Allah, baik ibadah vertical transcendental maupun ibadah horizontal, yang kita kenal dengan ibadah sosial. Menebar perdamaian, membantu ekonomi yang lemah, miskin papa, demi tegaknya pesaudaran sejagat, memperbanyak amal kebaikan dengan cara bersedekah, berimpak, agar tercipta kemakmuran rakyat bersama dalam naungan Tuhan Yang Maha Kuasa.

Inilah sebenarnya kesalahan-kesalahan penafsiran tentang jihad, yang dijadikan sebagai alat pembenaran oleh mereka dari kalangan beraliran garis keras (kelompk radikal dan fundamentalis) dalam Islam untuk melakukan ekspresi radikalisme dengan memakai symbol agama. Sebagaimana yang dinyatakan oleh alQardhawi dalam bukunya As-Sabwah al-Islamiyyah Baina al-Jubud wa-al Tajarruf, bahwa faktor utama munculnya sikap radikal dalam beragama adalah kurangnya pemahaman yang benar dan mendalam atas esensi ajaran agama Islam itu sendiri. Islam hanya dipahami secara dangkal dan parsial. ${ }^{24}$

Fundamentalisme dan radikalisme adalah merupakan aliran yang berpegang teguh pada "fundament" agama melalui penafsiran terhadap kitab suciagama secara literalis. Ide dasar aliran ini, kurang lebih sama dengan fundamentalisme dan radikalisme Kristen ${ }^{25}$, yaitu kembali kepada fundamental (dasar-dasar) agama secara "total" dan "literal", bebas dari kompromi, dan tidak mengenal

${ }^{23}$ Ibid. Lihat juga Ahmad Mustafa al-Maraghi, Tafsir al-Maraghi, jilid III (Beirut: Dar al-Fikr, 2001), hlm. 52-53.

${ }^{24}$ Lihat Yusuf al-Qardhawi, as-Sahwah al-IsTamiyyah Baina al-Juhud wa al-Tajarruf, hlm. 59-67.

${ }^{25}$ Lihat Roxanne L. Euben, Musub dalam Cermin, Fundamentalisme Islam dan Batas Rasionalisme Modern (Jakarta: Serambi, 2002). Lihat juga John L. Esposito, Unholy War: Teror Atas Nama Islam (Yogyakarta: Ikon, 2003). 
interpretasi. Namun dalam perkembangannya dalam konteks modern sekarang, aliran aliran radikal tersebut, sangat dipengaruhi oleh faktor politik, daripada aspek teologis- sosialnya.

Di kalangan beraliran radikalisme dan fundamentalisme, Islam bukan hanya dipandang sebagai alternatife ideologis, tetapi merupakan keharusan teologis dan praktik yang harus dilakukan secara bersamaan. Selain bersandar pada akar teologis, juga menggunakan instrumen "jihad", yang diartikan sama dengan "perang". Konsep jihad ini, sering kali dilegitimasi oleh kalangan Isam fundamentalis dan radikal untuk melakukan tindakan teror, seperti yang sekarang ini marak terjadi di berbagai kawasan dunia, termasuk Indonesia. Alasan yang mendasari berjihad bagi kalangan beraliran keras ini, ialah Q.S. al-Baqarah [2]: 120, yang artinya: "Tidak akan rela, baik Yahudi maupun Nasrani, sehingga engkau tunduk kepadanya". Ayat ini dipahami, bahwa orang Yahudi maupun Nasrani adalah pihak yang harus diwaspadai, karena selalu menyerang akidah kaum Muslimin. Implikasi dari pemahaman yang literalistic ini dalam sejarah dapat dilihat ketika terjadi Perang Salib antara umat Islam dan Kristen selama lebih 300 tahun.

Selanjutnya, fundamentalisme agama dalam al-Qur'an sebagai kitab suci banyak mengandung aturan berbagai dimensi kehidupan umat manusia, di antaranya pengaturan mengenai sistem pemerintahan dan kenegaraan. Namun, secara pemahaman penafsiran al-Qur'an, hal tersebut merupakan landasan teologi politik.

Berbasis pada konstruksi analisis di atas, dapat kiranya menjadi catatan penting bahwa beginilah cara metodologi penafsiran dan berpikir dari kalangan kaum radikal dan fundamentalis. Sesuai asas radikalisme dan fundamentalisme, yaitu kembali kepada ajaran yang pertama (al-Qur'an) sebagai satu-satunya pedoaman hidup. Mereka memahami nash-nash alQur'an secara literal (harfiah) sesuai apa adanya yang terdapat dalam teks. Mereka tidak mau tahu, apa sebenarnya tujuan alQur'an diturunkan untuk manusia melalui Nabi Muhammad saw. Mereka juga tidak melihat kembali bagaimana kondisi sosial 
(asbabun nuгul) dari ayat-ayat tersebut. Banyak pendekatan yang dapat digunakan dalam memahami nash al-Qur'an, agar alQur'an benar-benar dapat membawa kemaslahatan umat.

Secara faktual, Allah menurunkan al-Qur'an di tanah Arab, dengan sendirinya menempatkan bahasa Arab melalui teks al-Qur'an sebagai landasan verbalisasi bagi firman-Nya, dan selanjutnya diobjekkan manusia dalam bentuk mushaf alQur'an. Dengan demikian, sesungguhnya wahyu Allah itu telah memasuki pelataran sejarah, dan otomatis terikat dengan kaidah sejarah yang bersifat kultural-empiris. Pesan-pesan Allah dalam al-Qur'an bersifat universal, dan diperuntukkan untuk seluruh manusia. Tetapi karena adanya keterikatan oleh dimensi ruang dan waktu membuatnya mengambil focus bahasa dan kultur Arab yang bersifat particular. Dimensi inilah yang seharusnya mampu ditangkap oleh seluruh penafsir teks-teks keagamaan, untuk membedakan mana wilayah yang particular dan mana yang wilayah esensial.

Perlu ditegaskan juga, bahwa al-Qur'an merupakan kitab suci yang universal, maka ayat-ayatnya harus dipahami secara holistickomprehensif, dan tidak diambil secara sepotong-sepotong (atomistic). Oleh sebab itu, ditawarkan pendekatan pemahaman dengan cara munasabah antar ayat. Pendekatan lain yang juga ditawarkan, adalah dengan melihat latar belakang kesejarahan turunnya ayat (asbabun nuzul) terhadap turunnya ayat-ayat tertentu atau khusus. Dengan teori-teori tersebut, diharapkan Al-Qur'an akan menjadi "kitab rujukan" di semua tempat dan sepanjang waktu untuk mencapai kedamaian dan kemaslahatan, sehingga akhirnya Al-Qur'an akan menjadi rạ̣matan li al-'alamin sepanjang masa.

\section{Terapi Radikalisme}

Faktor pemicu munculnya kelompok garis keras dalam Islam, atau kemudian disebut sebagai kelompok radikal sangat terkaitdenganisu-isukemiskinan, kesenjangansosial, ketidakadilan ekonomi dan politik. Perilaku elite politik yang tidak akomodatif terhadap kepentingan rakyat, dan mengabaikan kepentingan rakyat, menjadi tempat persemaian subur bagi berkembang 
biaknya kelompok radikalisme dan funadamentalisme dalam Islam. Karena itu, memberangus radikalisme tidak cukup dengan cara menangkap, serta menggiring para pelaku kelompok radikal yang kemudian menjadi teroris ke pengadilan. Bahkan hukuman mati tidak cukup untuk memadamkan aksi-aksi teror kelompok garis keras ini. ${ }^{26}$

Perbaikan kehidupan masyarakat, dari kesengsaraan menjadi kesejahteraan, dari kebodohan menjadi kecerdasan, dari ketidakadilan hukum menjadi keadilan hukum, serta dari peminggiran menjadi kerjasama, merupakan hal yang harus dilakukan oleh pemerintah dan segenap aparatur Negara lainnya. Kasus dari berbagai pemboman di Indonesia sepanjang pasca tumbangnya rezim Orde Baru, adalah hal yang menunjukkan adanya tingkat kekecewaan yang sangat tinggi kepada rezim politik penguasa, sehingga jalan kekerasan menjadi alternative penyelesaian, yang kenyataannya membawa korban harta benda dan jiwa manusia. ${ }^{27}$

Dalam kasus Indonesia, penerapan syari'at Islam secara formal bukan hanya mimpi sebagian besar umat Islam, tetapi juga sebaliknya menjadi kecemasan banyak pihak, termasuk juga umat Islam sendiri. Di sisi lain, diversitas agama dan budaya merupakan fakta yang tidak mungkin diabaikan. Bagaimana universalitas Islam berhadapan dengan fakta diversitas agama dan

${ }^{26}$ Lihat Muhammad Khamdan, "Rethinking Deradikalisasi: Konstruksi Bina Damai Penanganan Terorisme", dalam Jurnal Addin, Vol. 9, No. 1, Februari 2015, hlm. 189-190. Lihat juga Mohammad Abu Nimer, Nir Kekerasan dan Bina Damai dalam Islam: Teori dan Praktek, terj. Irsyad Rafsyadi dan Khairil Azhar (Bandung: Alfabeta dan Paramadina, 2010), hlm. 235-246.

${ }^{27}$ Lihat Ted Robert Gurr, Why Men Rebel (USA: Princeton University Press, 1969). Dalam buku ini Robert Gurr mengintrodusir bahwa kekecewaan atas rezim politik akan sangat mungkin menumbuhkan kekerasan yang mendalam, sehingga melahirkan pemberontakan atas sistem yang berjalan. Penjelasan khusus mengenai masalah ini dapat dilihat pada Bab 3 dan Bab 4 buku tersebut. Lihat juga David Martha, Psychology of Religion (England: Oxford, 2002), hlm. 192. Lihat juga Bilveer Singh, Talibanization and Extrimisme in Southeast Asia (Singapore: ISEAS, 2007), hlm. 234. Lihat juga, Mark Jurgensmeyer, Teror in the Mind of God ( California: University of California Press, 2001), hlm. 230. Religion, Globalization, and Civil Society (Toronto: Sage Publikation, 2009). 
budaya? Bagaimana kesetiaan kepada keimanan memungkinkan seseorang hidup dalam keragaman budaya dan fakta diversitas tersebut? Kondisi multi kultur dan pluralisme adalah hal yang tidak mungkin ditolak keberadaannya. Namun, ada sebagaian umat Islam masih tetap menolak istilah multikulturalisme dan pluralisme, sebab kedua istilah ini menurutnya adalah sebuah paham untuk meniadakan perbedaan agama dan budaya. Istilah ini dikhawatirkan akan mempengaruhi tingkat keimanan masyarakat Islam. Padahal istilah multikulturalisme dan pluralisme merupakan istilah yang paling representative untuk menggambarkan kondisi masyarakat Indonesia sekarang ini. ${ }^{28}$ Hakikatnya, syari'at Islam bukan sekedar "penal code", tetapi merupakan sebuah visi global yang dapat memancarkan pencerahan universal untuk seluruh mahluk Tuhan kapanpun dan di manapun ia berada. Ia adalah sebuah konsep hidup dan mati (weltanschaung) yang berasal dari bacaan normatife dari sumber otoritas Islam, tetapi memungkinkan untuk dieksternalisasikan, sehingga memunculkan sebuah makna global dan memberi refleksi fungsional dalam kehidupan. Gagasan melakukan internalisasi dalam perspektif sosiologis, sebenarnya merupakan sebuah bangunan yang menghendaki adanya pemahaman yang memadai, dan disebarluaskan kepada publik, sehingga suatu saat nanti akan menjadi pemahaman publik. ${ }^{29}$

Apabila kita mendefinisikan syari'at sebagai sebuah visi global, maka kita harus mengintegrasikan dalam persepsi kita mengenai bagaimana tetap setia dalam keimanan kita dan menganggap bahwa semua yang baik adalah bagian dari syari'at. Misalnya, apabila kita membaca sebuah peraturan di Negara kita Indonesia ini, di dalamnya terdapat konsep tentang keadilan, maka kita harus menerimanya; bukan hanya karena kita memiliki

\footnotetext{
${ }^{28}$ Lihat Zuly Qodir, "Kesalahpahaman Multikulturalisme", Kompas, 26 Februari 2013.

${ }^{29}$ Lihat Peter L. Berger dan Thomas Luckman, Tafsir Sosial atas Kenyataan: Kajian Sosiologi Pengetahuan (Jakarta: LP3ES, 1987), hlm. 225. Lihat juga Karl Manheim, Sosiologi Pengetabuan: Pertautan Pengetabuan dan Politike (Yogyakarta: Kanisius, 1992), hlm. 226. Lihat juga R. Scott Appleby, The Ambivalency of the Sacred (USA: Maryland, 2004), hlm. 23.
} 
kontrak moral kesetiaan sebagai warga Negara, tetapi juga karena merupakan bagian kesadaran terdalam kita tentang ajaran syari'at. Dengan mengikuti perintah konstitusi Negara, berarti kita telah bersyari'at dan mengindonesiakan syari'at. Kita tidak diperbolehkan untuk bermental ganda. Artinya, ketika sesuatu untuk diri kita sendiri maka itu adalah baik, tetapi ketika sesuatu untuk orang lain adalah tidak baik. Keimanan model seperti ini, oleh Ninian Smarth disebut sebagai sebuah toleransi yang malas (laay tolerance), karena menganggap pihak sendiri yang paling baik dan benar, sementara pihak lain adalah salah. ${ }^{30}$

Umat Islam harus merevitalisasi dan meletakkan divinitas dan universalitas keimanannya dalam konteks sosial, budaya, ekonomi, dan politik. Artinya harus ada perbedaan yang jelas, antara keimanan kepada Tuhan dan ketaatan kepada peraturan Negara. Inilah yang kemudian disebut sebagai gagasan agama publik. Sebagai agama publik, berarti bagaimana hubungan kita dengan Tuhan, hubungan kita dengan wahyu telah memaksa kita memahami diversitas kemanusiaan dan budaya. Kita juga tidak setuju dan mau merelatifikasi nilai-nilai universal agama, tetapi yang penting ialah bagaimana nilai universal itu dapat mengakomodir "diversity of human and civilization". Inilah gagasan dari civil religion yang belakangan ini kita kenal dengan sebutan agama publik. Agama sebagai sebuah keyakinan pribadi hadir di tengah banyak orang yang berbeda-beda agama, etnis, kultur serta kelas sosial. ${ }^{31}$

Dalam perspektif ini, maka syari'at adalah eksternalisasi dari sebuah sumber yang "divinely revealed" yang memiliki validitas

${ }^{30}$ Lihat Ninian Smarth, One God and Others Name in the World (USA: Temple University Press, 2002), hlm. 112.

${ }^{31}$ Lihat Jose Casanova, Agama Publik: Agama di Era Modern (Malang: Riset dan UMM Press, 2007), hlm. 230. Lihat juga Robert N. Bellah, Beyon Belief: Gagasan tentang Civil Religion di Amerika (Jakarta: Paramadina, 2003), hlm. 23. Lihat juga Mohammad Nurul Huda, Aku Mantan Teroris (Bandung: Mizan, 2010), hlm. 35. Buku ini berisi kesaksian-kesaksian para pelaku Bom terkait dengan aksi-aksi yang dilakukan selama menjadi bagian dari aktivis radikalisme Islam. Mohammad Nurul Huda sendiri sekarang ini aktif dalam program "Deradikalisasi Islam" dengan cara memberikan beasiswa pendidikan kepada anak-anak mantan teroris yang Bapaknya ditangkap dan dipenjarakan. 
universal dan pandangan hidup yang komprehensif, bukan hanya karena karakteristik budaya dari sebuah komunitas tertentu yang datang dari luar Indonesia. Tetapi syari'at yang kompatibel untuk semua tempat dan waktu, dengan syarat bahwa harus mengalami penyesuaian dengan waktu dan tempat di mana ia dipedomani. Misalnya, kalau di Amerika, syari'at dapat menentramkan hati orang Islam dan orang Amerika kalau syari'at di amerikakan. Di Eropa, syari'at menjadi sumber inspirasi dan memberi ketenangan hidup, serta mendekatkan umat Islam Eropa dengan Tuhannya lewat syari'at yang dieropakan. Inilah yang disebut sebagai syari'at kontekstual.

Gagasan syari'at kontekstual dan penerapannya sesuai kondisi wilayah di mana umat Islam berdomisili, pernah digagas oleh Ahmed An-Na'im ketika menggagas tentang "Syari'at Demokratik". Syari'at model ini, ialah tidak membelenggu umatnya, tetapi sebaliknya membuat umatnya dalam melakukan aktifitas syari'atnya sesuai dengan kondisi zaman dan wilayah, sebab rumusan praksisnya seringkali berurusan dengan masalah lokalitas, bukan masalah universal. ${ }^{32}$

Syari'at tidak hanya menjadi sebuah visi global, tetapi juga menjadi rahmat bagi seluruh alam. Cara menjalankan syari'at seperti ini telah dicontohkan oleh Nabi dan para sahabatnya ketika membangun masyarakat di Madinah, bahkan Undangundang yang disusun oleh Nabi Muhammad saw dalam bentuk "Piagam Madinah" mengakomodir dan melindungi semua agama dan kepercayaan dari berbagai aliran dan kelompok, baik Yahudi maupun Nasrani. Hal ini seharusnya menjadi inspirasi dan rujukan umat Islam di seluruh dunia, termasuk umat Islam di Indonesia. ${ }^{33}$ Jadi melaksanakan syari'at tidak harus melakukan revivalisme apalagi radikalisme atau mengembalikan syistem khilafah, baik dengan cara intelek dan politik, seperti kasus HTI (Hizbut Tahrir

${ }^{32}$ Lihat Zuly Qodir, Syariah Demokratik. (Yogyakarta: LKiS, 2001), hlm. 35. Lihat juga Edward W. Said, The Mind of Terrorism (USA: Booksmaxwell, 2006), hlm. 24. Lihat juga Abdul Munir Mulkhan, Pengantin Bom dan Radikalisasi di Indonesia (Yogyakarta: Filosofi, 2011), hlm. 204.

${ }^{33}$ Lihat Muhammad Chirzin, dkk., Belajar dari Kisah-kisah Para Sababat (Yogyakarta: Jaringan Intelektual Muhammadiyah, 2005), hlm. 234. 
Indonesia), maupun dengan cara radikal seperti yang dilakukan oleh organisasi Jamaah Anshorut Taubid, dan Majelis Mujahidin Indonesia (MMI). Melaksanakan syari'at tidak harus mendirikan Negara Islam Indonesia (NII). Melaksanakan syari'at tidak harus melakukan tindakan anarkis dan brutal, seperti yang dlakukan oleh organisasi Front Pembela Islam (FPI) di beberapa tempat di Indonesia.

\section{Simpulan}

Dalam perspektif sejarah, gerakan radikalisme dalam Islam telah muncul di masa Khalifah Ali bin Abi Thalib, dengan munculnya golongan Khawarij yang memberontak atas ketidak setujuannya dengan tahkim yang memenangkan musuh, yakni dari kelompok Muawiyah. Kelompok Khawarij ini dagolongkan sebagai gerakan radikalisme Islam klasik. Dari analisis sejarah ini, dapat diketahui bahwa cikal bakal lahirnya aliran atau kelompok maupun organisasi Islam radikal kontemporer, adalah bersumber dari sejarah Islam itu sendiri, yang mulanya dipelopori oleh kelompok Khawarij yang keras kepala, tidak mengenal kompromi dan dialog. Kelompok inilah yang kemudian sekarang bermetamorfosis dalam bentuk Hizbut Tahrir Indonesia (HTI), Majelis Mujahidin Indonesia (MMI) dan Anshorud Tauhid, bahkan juga Front Pembela Islam (FPI). Meskipun tidak ditemukan bukti empiris kesejarahan yang kuat tentang pengaruh langsung ajaran Khawarij terhadap HTI, MMI, Anshorud Tauhid, dan FPI, tetapi penulis berkeyakinan terdapat unsur-unsur atau nilai-nilai Khawarij dalam gerakan organisasi radikal tersebut. Justifikasinya ialah, kelompok organisasi ini sama kerasnya dengan Khawarij, yaitu tidak mau menempuh dialog, jalan moderat dan persuasive.

Selanjutnya, mengenai persoalan tafsir ayat Al-Qur'an yang menjadi justifikasi kekerasan oleh kelompok radikal, perlu dilakukan usaha intensif oleh kalangan muballigh, ulama, tokoh agama, guru agama, dosen agama, para Kiyai di Pondok Pesantren untuk melakukan sosialisasi penafsiran secara murni dan tuntas berdasarkan metodologi tafsir ilmiah. Hal ini dilakukan untuk memberikan pengetahuan dan pemahaman yang benar kepada 
para peserta didik, pelajar, mahasiswa, dan kalangan santri agar tidak terjebak dalam kesalahan menafsirkan ayat-ayat yang terkait dengan istilah "jihad". Karena dalam Islam tidak mengenal cara-cara kekerasan dalam mencapai tujuan. Perdamaian merupakan sesuatu yang mendasar, dan setiap Muslim wajib mengusahakannya. Jihad yang benar adalah berjuang dengan segala tenaga, pemikiran, dan mental untuk mewujudkan perdamaian dan keadilan di tengah-tengah masyarakat. Tidak benar, bahwa Islam adalah agama kekerasan dan agama radikal. Pandangan dan tindakan radikal atas nama Tuhan dalam Islam sangat bertolak belakang dengan konsep "rạ̣matan li al-'alamin". 


\section{DAFTAR PUSTAKA}

Abdullah, Junaedi, "Radikalisme Agama: Dekonstruksi Ayat Kekerasan dalam Al-Qur'an", dalam Jurnal Kalam, Vol. 8, No. 2, Desember 2014.

Ayyubi, Nazih, Political Islam: Religion and Politics in the Arab World, London and New York: Routledge, 1991.

as-Ashmawy, Muhammad Said, Against Islamic Extrimism: the Writings Muhammad Said al-Ashmany, Florida: University of Florida, 1998.

al-Maraghi, Ahmad Mustafa, Tafsir al-Maraghi, Jilid III, Beirut: Dar al-Fikr, 2008.

al-Qardhawi, Yusuf, Al-Sahwah al-Islamiyyah Baina-al-Juhud wa al-Tarruf, Kairo: Bank al-Taqwa, 2001.

Amstrong, Karen, Berperang Demi Tuhan: Fundamentalisme dalam Islam, Kiristen dan Yahudi, Jakarta: Serambi, 2001.

Azra, Azyumardi, Pergolakan Politike Islam, Bandung: Mizan, 1999.

, Pergolakan Politik Islam: dari Fundamentalisme, Nodernisme, hingga Post-Modernisme, Jakarta: Paramadina, 2006.

Binder, Leonard, Islamic Liberation: A Critique of Development Ideologies, Chicago and London: The University of Chicago Press, 1988.

Casanova, Jose, Agama Publik, Agama di Era Modern, Malang: Riset dan UMM Press, 2007.

Gholib, Ahmad, Teologi dalam Perspektif Islam, Jakarta: UIN Syarif Hidayatullah, 2005.

Chirzin, Muhammad, dkk., Belajar dari Kisah-kisah Para Sahabat, Yogyakarta: Jaringan Intelektual Muhammadiyah, 2005.

Dikmejian, R. Hrair, Islam in Revolution, Fundamentalism in the Arab World, New York: Sycracuse University Press, 1985.

Engineer, Asghar Ali, "Islam and Doctrines of Peace and Non-Violence", dalam Jurnal Internasional Ibya Ulumuddin, Semarang: Program Pascasarjana IAIN Walisongo, 2001. 
Esposito, John L., The Islamic Threat, Myth of Reality, New York: Oxford University Press, 1992.

, Unholy War: Terror Atas Nama Islam, Yogyakarta: Ikon, 2003.

Euben, Roxanne L, Musub dalam Cermin: Fundamentalisme Islam dan Batas Rasionalisme Modern, Jakarta: Serambi, 2002.

E. Marty, Martin dan R. Scoot Appleby, Fundamentalisme Observed, Chicago and London: The University of Chicago Press, 1994.

E. Marty, Martin, "What is Funadamentalism Theological Perspective", dalam Hans Kuhn dan Jurgen Moltmann (eds.), Fundamentalism as a Cumanical Challenge, London: Mac Millan, 1992.

Farouki, Suha' Taji, "Islamist and Threat of Jihad: Hizb-al Tahrir and Muhajiroun on Israel and Jews", dalam Middle Eastern Studies, 36:4, Oktober, 2000.

Farouki, Suha' Taji, A Fundamental Quest: Hið̧b al-Tahrir and the Search for the Islamic Caliphate, London: Grey Seal, 1996.

Fealy, Greg, "Hizbut Tahrir in Indonesia: Seeking a Total Islamic Identity", dalam Shahram Akbarzadeh dan Fethi Mansouri (eds.), Islam and Political Violence: Muslim Diaspora and radicalism in the West, London and New York: Tauris Academic Studies, 2007.

Gurr, Ted Robert, Why Men Rebel?, USA: Princeton Universty Press, 1969.

Hitti, Philip K., History of the Arabs, London and Basing Stoke: The MacMillan Press Ltd., 1974.

Hizbut Tahrir Organization, The Metodology of Hizbut Tabrir of Change, London: al-Khilafah Publikation, 1999.

Jahroni, Jajang dan Jamhari, Gerakan Salafi Radical di Indonesia, Jakarta: Raja Wali Press, 2004.

Jurgensmeyer, Mark, Terror in the Mind of God, California: California University Press, 2001.

, Religion, Globalization, and Civil Society, Toronto: Sage Publikation, 2009.

Karagiannis dan Clarc McCauley, "Hizbut Tahrir al-Islami: 
Evaluating the Threat Posed by a Radical Islamic Group that Remannis Non Violence", dalam Terrorism and Political Violence, No. 58, (2006).

Khamdan, Muh. "Rethinking Deradikalisasi: Konstruksi Bina Damai Penanganan Terorisme", dalam Jurnal Addin, Vol. 9, No. 1, Februari 2015.

L. Berger, Peter, dan Thomas Luckman, Tafsir Sosial atas Kenyataan: Kajian Sosiologi Pengetahuan, Jakarta: LP3ES, 1987.

Martha, David, Psychology of Religion, England: Oxford University Press, 2002.

Manheim, Karl, Sosiologi Pengetabuan: Pertautan Pengetabuan dan Politik, Yogyakarta: Kanisius, 1992.

Munir Mulkhan, Abdul, Pengantin Bom dan Radikalisasi di Indonesia, Yogyakarta: Filosofi, 2011.

N. Bellah, Robert, Beyon Belief: Gagasan Tentang Civil Religion di Amerika, Jakarta: Paramadina, 2003.

Nasution, Harun, Teologi Islam: Aliran-aliran Sejarah, Analisa Perbandingan, Jakarta: UI Press, 1986. , Islam Rasional: Gagasan dan Pemikiran Prof. Dr. Harun Nasution, Bandung: Mizan, 1996.

Nurul Huda, Muhammad, Aku Mantan Teroris, Bandung: Mizan, 2010.

Qadir, Zuly, Syari'ah Demokratik, Yogyakarta: LKiS, 2001. "Deradikalisasi dalam Perspektif Pendidikan Agama", Jurnal Pendidikan Islam, Vol. II, No. 1, Juni 2013.

Rokhmad, Abu, "Radikalisme Islam", dalam Jurnal Walisongo, Vol. 20, No. 1, Mei 2012, Semarang: IAIN Walisongo, 2012.

Rijal, Syamsul, "Radikalisme Klasik dan Kontemporer", Alfiker, Vol. 28, No. 2 (14) 2010.

Singh, Bilveer, Talibanization and Extrimism in Southeast Asia, Singapore: ISEAS, 2007.

Syalabi, Ahmad, Sejarah Kebudayaan Islam, Jilid I, Jakarta: Pustaka al-Husna, 1994.

Smarth, Ninian, One God and Others Name in the Word, USA: Temple University Press, 2002. 